\title{
WHAT DOES EVERY ESOL TEACHER NEED TO KNOW? CLOSING PLENARY ADDRESS AT THE 2012 CLESOL CONFERENCE IN PALMERSTON NORTH
}

\author{
Paul Nation, LALS \\ Victoria University of Wellington
}

\section{Two books for teachers}

This year (2012), two books will appear which are basic texts designed for teachers who have not had specialist training in language teaching. They are an attempt to answer the question "What are the basic things a teacher should know in order to teach English to speakers of other languages?”.

Nation, Paul. (in press). What does every ESL teacher need to know? Seoul, South Korea: Compass Media. (available free in electronic form when published)

Nation, Paul. (in press). What does every EFL teacher need to know? Seoul, South Korea: Compass Media.

I wrote the book about EFL (English as a Foreign Language) first and was going to stop there, but then I also saw a need for a book about English as a Second Language. Before writing the ESL book, I thought that I might be able to use several of the chapters from the EFL book in the ESL book, but what surprised me was how different the two books turned out to be. There are of course very strong similarities too because the principles and many of the techniques of language teaching remain basically the same even though English is taught in two quite different situations. The major differences are outlined in Table 1.

\section{ESL and EFL}

Table 1:

Comparing the Features of ESL and EFL Teaching

Features

Language needs

Motivation

\section{ESL}

There are strong and immediate language use needs outside the classroom.

Because of immediate and long term needs, motivation is typically very high.

\section{EFL}

Often the learning has no obvious purpose.

Motivation depends heavily on the quality of the teaching, and courses may be compulsory, which is not usually good for motivation. 
Comparing the Features of ESL and EFL Teaching cont.

Features

Opportunities

for learning

Cultural

content
ESL

A wide range of opportunities for learning exist outside the classroom.

There are immediate cultural needs.
EFL

Classroom activities may be the most significant source of input and language use.

Much of the language learning may not be affected by cultural needs.

For me, the most striking difference is that ESL learners have obvious and immediate language use needs, and these needs affect the other three features of motivation, opportunities for learning, and the importance of cultural content. Well over one third of the ESL book is about needs analysis. Those chapters describe what needs analysis and environment analysis are, how to gather needs and environment analysis information, and what we already know about learners' needs in various teaching situations like one-to-one teaching, teaching small classes, teaching within the school system, teaching English to job seekers, and teaching English for academic purposes.

In Table 1, the list of features in the EFL column is rather negative, and this reflects the difficult task that EFL teachers face. It is much easier to learn a language in the country where it is spoken than to learn it as a foreign language. This is not true for all learners, and the learners who go against this trend would be an interesting study in themselves. Rather than follow the organization of the books, I want to look at the important shared principles which should lie behind language teaching and the activities which bring these principles into practice. I have ranked the principles in order of importance, and I have chosen what I think are the most important language teaching activities. I will also indicate what I think is the most useful language teaching activity.

\section{Principles}

\section{1) Needs and motivation}

Language courses should directly address the needs of learners who do the courses. This seems obvious, but this principle is not always put into practice. An important way of addressing the needs of adult learners is to use a negotiated syllabus, where the teacher and the learners negotiate the content of the language course and how it will be taught and assessed. Negotiated syllabuses still draw heavily on the teacher's experience and expertise but make sure that the needs of the learners are properly taken into account. It is not essential to use a negotiated syllabus, but the teacher should look carefully at learners' needs and how to address them. 


\section{2) The four strands}

The second most important principle involves having a well-balanced program which provides for different opportunities for language learning, learning through (1) meaning-focused input, (2) meaning-focused output, (3) language-focused learning, and (4) fluency development. Each of these four strands should have roughly equal amounts of time in a course. The principle of the four strands applies much more strongly where English is taught as a foreign language than where English is taught as a second language. However, even where English is taught as a second language, it is worth checking to see that the four strands are represented in the course and that no particular strand is strongly overrepresented or under-represented.

\section{3) Input}

The principle of providing comprehensible input is contained in the idea of the four strands. However, this is such an important principle that teachers need to make sure that the learners are doing plenty of listening and reading which is at the right level for them. In an ESL situation, getting enough listening input is usually not a major issue, but it is also important that learners are doing a lot of relevant reading which is at the right level for them. This is particularly important when learners are in the school system.

One of the problems with gaining enough reading input is that graded readers end at around the 3000 word level, but learners need around 8000 to 9000 words to be able to read unsimplified text with any comfort. To fill this gap, we have created midfrequency readers adapted for advanced learners who know 4000, 6000, or 8000 word families. Each reader is available at each of the three levels, and all of the readers produced so far are available free on Paul Nation's website. We are keen to find volunteers to help create such readers, as the goal is to have at least fifty of them, each at each of the three different levels. It takes about 10 hours to create the three versions.

\section{4) Time on task}

The time on task principle simply says that the more you do something, the better you will become at doing it. This somewhat crude principle is remarkably effective. It does not mean however that learners should struggle with material and tasks which are far too difficult for them. It does mean though that they should do substantial amounts of listening, speaking, reading, and writing in order to improve these skills. If learners find difficulty in reading, this should not be a reason for the teacher to find other ways of presenting the subject matter that they need to know. It should be a reason for providing substantial amounts of relevant and supported reading so that they can develop this important skill.

\section{5) Direction of effort}

This principle simply says that we learn what we focus on. If we focus on gaining or communicating meaning, then that is what we will learn. If we focus on the form of 
items, then that is what we will learn. Both of these focuses are helpful, but teachers need to look carefully at the activities they use, and what the learners are actually doing during the activity. Is the focus of the learners' attention on what the teacher wants them to learn?

Let us now look at what I consider to be the most important activities in a language course.

\section{The most useful language teaching techniques}

Table 2 contains what I consider to be the most useful language teaching techniques. The ways in which these techniques are used will differ to some degree in various teaching situations and for various ages and levels of learners.

Table 2:

The Twenty Most Useful Language Teaching Techniques

\begin{tabular}{|c|c|c|}
\hline Skill area & Technique & Strand \\
\hline \multirow[t]{3}{*}{ Listening } & Listening to stories & Meaning-focused input \\
\hline & $\begin{array}{l}\text { Read and listen } \\
\text { (controlled listening) }\end{array}$ & Meaning-focused input \\
\hline & Dictation & Language-focused learning \\
\hline \multirow[t]{7}{*}{ Speaking } & Pair conversation & Meaning-focused output \\
\hline & Prepared talks & Meaning-focused output \\
\hline & $\begin{array}{l}\text { Problem-solving speaking } \\
\text { (role play) }\end{array}$ & Meaning-focused output \\
\hline & Same or different (pronunciation) & Language-focused learning \\
\hline & Identifying (pronunciation) & Language-focused learning \\
\hline & Observation tasks & Language-focused learning \\
\hline & 4/3/2 (Repeated speaking) & Fluency development \\
\hline \multirow[t]{4}{*}{ Reading } & Extensive reading & Meaning-focused input \\
\hline & Paired reading & Meaning-focused input \\
\hline & Intensive reading & Language-focused learning \\
\hline & Speed reading & Fluency development \\
\hline \multirow[t]{3}{*}{ Writing } & Writing with feedback & Meaning-focused output \\
\hline & Substitution tables & Language-focused learning \\
\hline & 10 minute writing & Fluency development \\
\hline \multirow{3}{*}{$\begin{array}{l}\text { General } \\
\text { purpose }\end{array}$} & Linked skills & Message-focused strands \\
\hline & Issue logs & Message-focused strands \\
\hline & Word cards & Language-focused learning \\
\hline
\end{tabular}

Most of these techniques will be well known to language teachers. They are all described in detail in the books that I mentioned at the beginning of this talk. However, I will briefly describe a few of the ones that some teachers might not 
recognise. Read and listen involves reading a text while listening to a spoken version of it. One of the great technological advances for listening is the availability of text to speech programs which can change written text into spoken language. Another important technological advance has been the ability to control the speed of spoken texts so that there is no distortion of the pitch during playback when the speed is slowed down or speeded up.

Observation tasks are particularly important where English is taught as a second language. In their simplest forms they involve the teacher providing the learners with a few simple questions to answer. They find the answers by observing native speakers either in real life or if necessary on TV. Here's an example.

What can you say to end a telephone conversation?

Besides what is said, is there anything about how it is said which signals the end of the conversation?

Such observation tasks can focus on spoken interaction, and can also focus on cultural issues such as meals or showing politeness to older people.

Paired reading involves learners working in pairs to read a text. The idea of working in pairs is so that the learners can get support during their reading.

Issue logs can also be called projects. They involve each learner choosing a topic which is of interest and relevance to them, gathering data on this topic, reporting to others in the small group at regular intervals about the data that they have gathered, and then eventually presenting both an oral report and a written report on what they have found. This activity stretches over several weeks.

If I had to go to a desert island and was only allowed to take one teaching technique with me, the one that I would take would be the linked skills activity. The linked skills activity involves focusing on the same piece of material through three of the four skills of listening, speaking, reading, and writing. So, the learners could read a text about a certain topic. Then they talk in small groups about what they have read. Finally, they work in pairs to write a summary of their reading and discussion. In this activity the same content is focused on across the three skills of reading, speaking, and writing. There are many variations of linked skills activities and they set up ideal conditions for vocabulary learning in that they provide the opportunity for repeated retrieval to occur, for negotiation to occur, and for varied use and varied meetings of the new vocabulary.

It is worth considering which of the techniques in Table 2 are teacher-centred, groupcentred, or involve independent work, because by classifying activities in this way, teachers can reduce their teaching load, giving responsibility to the learners for many of the activities. 


\section{How could you make a substantial change to your English program?}

If a teacher wanted to make a substantial change to their teaching program, what could they do? Here, substantial means a change that would have a strong effect on learning. It does not mean a change that would require changing the complete nature of the program. Any one of the following changes would have a very good effect on an English program. The ranked most significant changes to a program are as follows:

1 Extensive reading at the appropriate levels for input and fluency development

2 A fluency development program

3 Peer listening and speaking

4 Linked skills activities

5 Vocabulary size testing

An extensive reading program is listed as the most significant change because this change is well researched and has been shown to bring about lots of different kinds of useful learning. It is also a relatively easy change to make, but the major requirement is the availability of reading material. Note that an extensive reading program should have a meaning-focused input strand where learners read material which is at the right level for them so that they are meeting a few unknown words and constructions. It should also have a fluency development strand where learners read easy material but read it quickly.

Fluency development is important and this is why the second most substantial change would be the introduction of a fluency development program across the four skills of listening, speaking, reading, and writing. The activities in Table 2 are classified into the four strands, and those in the fluency development strand are clearly indicated.

Peer listening and speaking activities provide opportunities for learners to learn from each other. Careful thought needs to be given to how pairs and groups are formed for such activities. Second language learners can benefit from being paired with native speakers of the language, and there are also benefits in cross-age peer tutoring.

I have already suggested that linked skills activities are probably the most useful of all teaching activities. This is likely to be because you get three for the price of one. Linked skills activities are very well known amongst primary school teachers but they may not be so well-known by other teachers. The ESL book I referred to earlier contains a chapter on linked skills activities.

The fifth change on my list is vocabulary testing. Over the last year I have been involved in a large vocabulary testing program looking at the vocabulary size of secondary school students. The findings of this research indicate that at each age level there is a wide range of vocabulary sizes, but even those native-speakers with the smallest vocabulary sizes have a large enough vocabulary to cope with their school 
work. The rule of thumb for working out the vocabulary size of a young nativespeaker is to take their age in years, take away 2, and multiply by 1000 . So a 13 -yearold is likely to have a receptive vocabulary size of around 11,000 word families (13 minus 2 times 1000). A 17 year old is likely to have a receptive vocabulary size of around 15,000 word families. Because learners do differ in their vocabulary sizes, it is worthwhile carefully measuring the vocabulary size of learners who need language support. The tests to do this are available free from my website. Careful measurement involves sitting next to the learner while they sit the test and encouraging them to stay on task and praising their successful answers. Such encouragement can increase their scores on the test so that their scores are a truer reflection of their knowledge.

\section{The teacher's jobs}

This talk has focused on teachers, teaching principles and teaching activities. Let me conclude by looking at the teacher's jobs. The teacher's main jobs are (1) to plan a good course (the most important job), (2) to organize learning opportunities both in and outside the classroom, (3) to train learners in language learning strategies so that they are encouraged to be independent in their learning, (4) to test learners to make sure that they are making progress and that they know how well they are doing, and finally, the least important but still important job, (5) to teach. The reason for listing these jobs is to show that planning and organizing opportunities for learning are by far the teacher's most important tasks. Teaching is something that the teacher should do but should not overdo. If we look at these jobs from the perspective of the four strands, teaching is part of the language focused learning strand and only a part of that strand. That means that teaching should make up less than one quarter of the course time. The rest of the course time has the learners involved in learning through input, output, and fluency development. The learners should also be responsible for some of their language-focused learning.

At this conference I was awarded the substantial honour of life membership of TESOLANZ. I usually avoid such honours but in this case I was very proud and pleased to accept. I was the first president of TESOLANZ and I have felt great pride and pleasure in being part of this organisation. The CLESOL conference is always very well attended, and for a country as small as New Zealand, the numbers attending are very large indeed. This is a tribute to the professionalism of English teachers in this country. As a gift to the profession, I have decided to make the book 'What does every ESL teacher need to know?' available free in electronic form. I am grateful to Compass Media for their support in doing this. In writing this book, I have had the generous support of several ESL teachers in New Zealand who are acknowledged in the book.

Note: Look on Paul Nation's web site (http://www.victoria.ac.nz/lals/staff/paul-nation.aspx) for Midfrequency readers, the Range program with lists going up to the $25^{\text {th }} 1000$, two parallel forms of the 20,000 Vocabulary Size Test plus a detailed description of the test. How to get a free copy of 'What does every ESL teacher need to know?' will also be explained there when the book is available. 